Article

\title{
Neighbourhood Park Vitality Potential: From Jane Jacobs's Theory to Evaluation Model
}

\author{
Federica Banchiero ${ }^{1}$, Ivan Blečić ${ }^{1}$, Valeria Saiu ${ }^{1, *(D)}$ and Giuseppe A. Trunfio ${ }^{2}$ \\ 1 Department of Civil \& Environmental Engineering and Architecture, University of Cagliari, 09123 Cagliari, \\ Italy; fede.banchiero@gmail.com (F.B.); ivanblecic@unica.it (I.B.) \\ 2 Department of Architecture, Design and Urbanism, University of Sassari, 07041 Alghero, Italy; \\ trunfio@uniss.it \\ * Correspondence: v.saiu@unica.it
}

Received: 15 June 2020; Accepted: 20 July 2020; Published: 22 July 2020

\begin{abstract}
We construct a method to evaluate the neighbourhood park vitality potential (NPV-potential), inspired by Jane Jacobs's theory of urban and park vitality. The evaluation model produces an aggregate score of NPV-potential by combining information on the extrinsic factors of vitality, related to the park's surrounding urban area, with evaluative judgements on the intrinsic factors, related to the park's internal organisation and design. To showcase and submit the evaluation model to a preliminary test drive, we further present the results of an application on three parks in the city of Cagliari, Italy. The computed NPV-potential and the effective use of the three parks, obtained from direct observation, show a good degree of agreement. While far from a robust validation, which would require more extensive empirical studies with larger and more internally variable samples of parks, the reported agreement between the potential and the observed vitality on the ground is a preliminary indication of the possible usefulness of the proposed evaluation method for urban planning and design.
\end{abstract}

Keywords: Jane Jacobs; neighbourhood parks; urban vitality; urban diversity; evaluation model; planning support

\section{Introduction}

The primary aim of this work is to propose an evaluation method of neighbourhood park vitality potential (NPV-potential), based on Jane Jacobs's theory of park vitality, as an aiding tool for urban planning and design.

The idea that urban green spaces can be a remedy for many problems ailing cities is the cause of excessive expectations often put on city parks, fostering projects and interventions that, once implemented, fail to produce the expected benefits. Jane Jacobs warned us that "too much is expected of city parks. Far from transforming any essential quality in their surroundings, far from automatically uplifting their neighborhoods, neighborhood parks themselves are directly and drastically affected by the way the neighborhood acts upon them" [1] (p. 90). Be it environmental sustainability, pollution reduction, environmental risks protection, economic development, urban liveability or the well-being of the inhabitants, the discrepancies between the declared and expected outcomes on one hand, and those actually produced on the ground on the other hand, are often due to the urban green spaces being treated as autonomous and self-referential objects and pieces of urban design, without an adequate assessment of how they may interact with the their surrounding and wider urban context. Differently from a naive determinism of a "green-oriented" urban development, to promote interventions that are effective in pursuing larger policy and planning goals, the spatial, functional and social features of the urban context surrounding urban green areas need to be taken into due account. 
Jane Jacobs pioneered the idea of context complexity as the basic "raw material" for urban planning and design. Her work, characterised by a strong attention to the relationship between people and their living environment, can be placed within the ecological movement [2-5], as Jacobs herself recognised in the foreword to the Modern Library Edition of her The Death and Life of Great American Cities [6]:

At some point along the trail I realised I was engaged in studying the ecology of cities. ( ... ) by city ecology I mean something different from, yet similar to, natural ecology as students of wilderness address the subject. A natural ecosystem is defined as "composed of physical-chemical-biological processes active within a space-time unit of any magnitude." A city ecosystem is composed of physical-economic-ethical processes active at a given time within a city and its close dependencies. I've made up this definition, by analogy.

Thirty years after the first edition, Jacobs had the opportunity to reflect on her work, initially conceived "merely to describe the civilizing and enjoyable services that good city street life casually provides" and "to deplore planning fads and architectural fashions", and ended up becoming a process of continuous discovery towards understanding the functioning of cities as complex ecosystems "vulnerable and fragile, easily disrupted or destroyed" [6]. Perhaps not coincidentally, the first edition of Jacobs's masterpiece was published around the same time of Rachel Carson's Silent Spring (1962) [7]. As Kinkela [4] (p. 905) noted, both books "invoked a common language to criticise physical geographies or landscapes that have often been considered incongruous", forging the underpinning of the concept of ecological landscape. The ecosystemic approach for understanding urban functioning proposed by Jacobs anticipated many now widely recognised principles of sustainable city, such as compactness, walkability, connectivity, accessibility, and diversity [8-11].

In this perspective, Jacob's arguments on the neighbourhood parks [1,12] still hold as highly relevant for planning and urban design, revolving around the criticism of an overly aestheticised conception of urban green, and the need to give proper consideration to the surrounding urban context. Her commentary includes examples of even well-designed and in principle pleasant parks, though so poorly used to make them fall into neglect and decay. Rather than on bad architectural and urban design, such destiny, Jacobs points out, largely hinges on their urban context, inadequate to foster an intense and diversified use of the green areas:

You can neither lie to a neighborhood park, nor reason with it. "Artist's conceptions" and persuasive renderings can put pictures of life into proposed neighborhood parks or park malls, and verbal rationalizations can conjure up users who ought to appreciate them, but in real life only diverse surroundings have the practical power of inducing a natural, continuing flow of life and use. Superficial architectural variety may look like diversity, but only a genuine content of economic and social diversity, resulting in people with different schedules, has meaning to the park and the power to confer the boon of life upon it. [1] (p. 96)

\subsection{Operationalising Jane Jacobs's Theory}

Despite the widespread recognition of the relevance of Jacobs's theory $[8,13-28]$-foundational, or at least a source of inspiration, for many subsequent refinements, extensions and applications by planners, scholars, and practitioners-for a long time her principles were applied without the support of explicit evaluation procedures and planning aiding tools. Relatively few attempts have been made to explicitly operationalise these principles, and even fewer were the attempts to codify them into formal quantitative evaluation procedures.

One of the first studies to test Jacobs's theory with formal statistical procedures was attempted in 1973 by John Weicher [29]. Using regression analysis applied to the neighbourhoods of Chicago, Weicher suggested that there is little confirmation of Jacobs's claims of the positive effects of the so called "four generators of diversity" - density, mix of uses, short blocks, aged buildings-although the author himself observed that the available data and the regression modelling employed do not fully 
reflect Jacobs's theoretical assumptions. Notwithstanding the actual results of this study, it has shown that Jacobs's theory is not just "verbalistic", and that attempts can be made to formulate and test it with formal quantitative methods.

The development of digital technologies and the growing availability of spatial datasets at the micro-urban level of the last two decades are increasingly removing some of the obstacles to engage and to submit Jacobs's theory to a more systematic empirical and quantitative exploration, as demonstrated by several recent studies. Sung et al. [30,31] attempt to operationalise and apply Jacobs's theory of urban life vitality on the city of Seoul, evaluating the relationship between walking activities and four measures of urban diversity. The study bares confirmative evidence of the correlation between metrics of the urban environment suggested (or inspired) by Jacobs's theory, and measures of vitality in different urban contexts and at different times of the day. In another study, Sung and Lee [32] analyse the relationship between the residential built environment and walking activity, whose results suggest that the explanatory power of Jacobs's theory of urban vitality is stronger at the neighbourhood rather than at the district level.

Recently, several scholars have made attempts to develop computation-intensive evaluation approaches using mobile phone data as a proxy for urban vitality. For example, De Nadai et al. [33] attempted to extract human activity from such data and, in combination with OpenStreetMap, Italian Census and land-use data from the Urban ATLAS project, bring evidence in support of Jacobs's theses from six Italian cities-Bologna, Florence, Milan, Palermo, Rome and Turin—which as urban contexts are markedly different from "the great American cities", and from the Asian mega cities studied by Sung et al.

Delclòs-Alió and Miralles-Guasch [34] operationalised and applied a Jacobsian quantitative analysis on the city of Barcelona in Spain. This study assigns a score for each identified condition of urban vitality and spatially analyses the results, mapping information about urban diversity on a district and neighbourhood scale. Another approach is proposed by Sulis et al. [35], using public transportation smart-card data to evaluate the spatio-temporal variations of urban vitality in the city of London, during different times of the day and on different days of the week, proposing an evaluative index capable of capturing two essential elements of vitality: the continuity in presence and the variety of people in places.

\subsection{Operationalising Jane Jacobs's Theory of Neighbourhood Park Vitality}

Differently from the aforementioned studies-whose focus is the assessment of urban vitality, that is, the vitality of urban areas, neighbourhoods or districts-the work presented in this paper focuses on the vitality of neighbourhood parks.

Jane Jacobs deemed parks "volatile places", subjected to, almost at the mercy of, the practices of use of the surrounding urban area. That is why "they tend to run to extremes of popularity and unpopularity" [1] (p. 89). Despite there being "dozens of dispirited city vacuums called parks, eaten around with decay, little used, unloved" [1] (pp. 89-90), Jacobs was dazzled by the persistence of uncritical views of the virtues of open spaces:

Ask a houser how his planned neighbourhood improves on the old city and he will cite, as a self-evident virtue, More Open Space. Ask a zoner about the improvements in progressive codes and he will cite, again as a self-evident virtue, their incentives toward leaving More Open Space. Walk with a planner through a dispirited neighbourhood and though it be already scabby with deserted parks and tired landscaping festooned with old Kleenex, he will envision a future of More Open Space. [1] (p. 90)

The idealised view of open spaces, and in particular of urban parks, underestimates the perils of a lack of use and the resulting decay, generating derelict and abandoned places, which in turn negatively affect the perceived quality of the surrounding environment. This criticism has been championed and extended by many others since Jacobs. For example, Bangs and Mahler 
(1970) [36] highlighted the relationship between the lack of use of neighbourhood public parks and the characteristics of urban space, the geometries of open space distribution, and their visual and pedestrian access. Similarly, Seymour Gold [37-39] criticised the traditional approaches to urban recreation planning, raising concerns over the serious impact a lack of use of neighbourhood parks may have on urban form and function. He remarked that "despite excellent weather, convenient access, and good development, maintenance, or program, observations indicate that neighbourhood parks are underutilized" [37] (p. 369). Gold notes that the neglect of the issue and of the implications of non-use were so remarkable, that the word "non-use" itself was difficult to encounter in the planning literature at the time. In seeking for possible factors for this state of things, he suggested that "the projected implications of non-use are related here to professional challenges for research and action" [37] (p. 369). Along this line, Moore and Jones [40] pointed at the planning process among the causes of this attitude and, in particular, at the absence of a realistic conception of the public interest such as equality and accessibility of urban service for all residents.

As for Jacobs's vision, starting from a critique of the traditional planning responsible for the drafting of "static plans" within "a Platonic vision of the city as an orderly and finished work of art" [41] (p. 128), she proposes an empirical approach to the study of non-use of neighbourhood parks, suggesting a set of extrinsic and intrinsic factors of their vitality [1,42]. The extrinsic factors are related to the contextual conditions surrounding the park area, while intrinsic factors refer to the design features which affect the use of the park.

As we said at the beginning, the primary aim of this work is to propose a urban planning and design aiding tool for the evaluation of neighbourhood park vitality potential (NPV-potential). To our knowledge, there are no studies attempting to employ the specific Jacobs's approach to construct an evaluation model of NPV-potential, combining the effects of the park's surrounding urban diversity, with the features of its internal organisation and design. There have been efforts to study distributive patterns of parks. Among these, a noteworthy example is the effort by Talen [43] to construct and empirically test normative principles for park distribution, drawing also on Jane Jacobs's theory, with reference to the spatial goals of proximity, diversity and social need. Whilst largely sharing the underlying methodological and cultural foundations, our approach here is, in a way, a reversal of such attempts. To put it in a brief formula: instead of looking at the distribution of parks to score a city or a neighbourhood, we look at the city and the neighbourhood to score the park, estimating its potential vitality.

The remainder of the paper is organised into four sections. In the next one (Section 2) we more systematically discuss the factors Jacobs deems relevant for park vitality. The factors are subdivided into (1) extrinsic features, related to parks' urban context and surrounding, following the logic of Jacobs's "four generators of diversity"; and (2) intrinsic features, related to parks' design and internal organisation. After that, in Section 2 we go onto constructing a logical bridge between Jacobs's theory and our evaluative approach, mapping concepts onto their formal representations within the evaluation model. Having constructed such a logical bridge, in Section 3 we present the formal specification of the evaluation model. To showcase the model, in Section 4 we present a comparative application on three parks in the city of Cagliari (Italy), and comment on its findings. Finally, in the conclusions (Section 5) we advance some general suggestions on the potential uses, and usefulness, of the proposed evaluative framework for planning and urban design practice.

\section{Neighbourhood Parks Vitality: A Bridge from Jane Jacobs's Theory to Evaluation Modelling}

To construct a formal evaluation model of the NPV-potential, we have made an attempt to logically map Jacobs's concepts presented in the previous section onto a set of variables and parameters in the evaluation model. These mappings are described in the next two subsections, following the above distinction between extrinsic and intrinsic factors of vitality. To help follow the text, in Figure 1 we present a conceptual scheme of the ingredients of the evaluation model. 


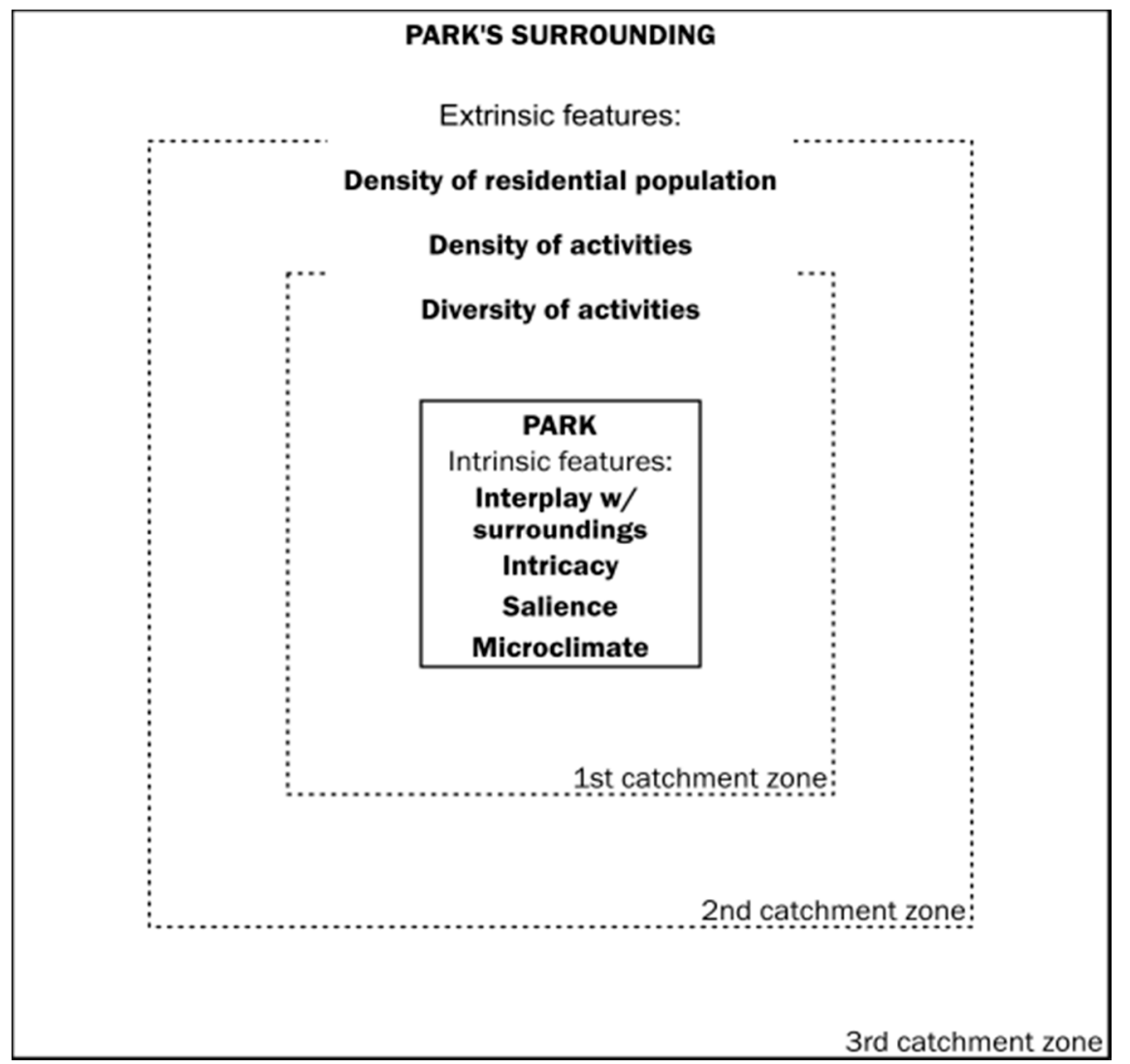

Figure 1. Conceptual scheme of the "ingredients" of the NPV-potential evaluation model.

\subsection{Extrinsic Factors: Generators of Urban Diversity}

Despite every park being a case in itself, Jacobs argued that parks' vitality greatly hinges on the general urban vitality in their surroundings, based on the presence of "four generators of diversity": density, diversity, short blocks and old buildings.

The first two generators-density and diversity - are related to social, economic, and functional features of the surrounding urban area. Starting from a critique of the low-density suburban type of urbanisation with a predominant residential vocation, Jacobs argues for the need to take greater account of the peculiar relationships between a dense concentration of people and diversity of uses. She warns us that this relationship cannot be assumed as a "simple and straight mathematical affair" [1] (p. 205): a plain concentration of inhabitants, in fact, is not in itself a guarantee of diversity and can lead to mere overcrowding. Large numbers of people can generate diversity only if the urban space offers diverse uses and types of activity. The combination of different uses together with the density therefore represents, according to Jacobs, a necessary condition of vitality. In making the distinction between "primary uses" (e.g., housing, offices and factories, large cultural institutions, recreational activities) and "secondary uses" (those that emerge for servicing and supporting the primary uses), Jacobs emphasises the effect of the "primary uses" in drawing people to a specific place, suggesting that these different uses should not exist in isolation, but should be combined in order to create a pool of mutual support. In this way a favourable environment for the growth of secondary uses is also created. Thus, in the specific case of neighbourhood parks, the presence of people moving around for different purposes and at different times of the day is an antidote against their lack of use. Diverse activities taking place around the clock, and contributing to the active street life and frontages, positively influence pedestrian flows (e.g., commercial, street markets, shops, independent businesses, cultural and meeting places) which sustain parks safety and extended use by different types of users. 
The other two elements of Jacobs's four generators of diversity-short blocks and old buildings-are related to the optionality provided by the patterns of urban layout and form. The idea of short blocks is tightly related to the concept of permeability and connectivity, offering frequent opportunities to turn corners and encourage pedestrian activity, providing a hospitable environment and creating more spatial opportunities for localizing activities. On the other hand, the age of buildings is related to the optionality provided by buildings in the neighbourhood to host a variety of economic activities, diverse also in terms of their added value and bid rent. A close-grained mix of buildings of different ages and conditions, argues Jacobs, provides affordable spaces and variable property sizes at different rent costs for small businesses [1,44]. The high costs of selling and renting new buildings may prevent the development of small businesses, necessary for the vitality, safety and public life of streets and neighbourhoods, while ordinary, low-value old buildings, including some degraded old buildings, available at more affordable costs, can accommodate "unformalized feeders of the arts-studios, galleries, stores for musical instruments and art supplies, backrooms where the low earning power of a seat and a table can absorb uneconomic discussions ( ... ) New ideas must use old buildings". In this sense, aged buildings can be engines of urban antifragility [45], representing potential incubators for new primary and secondary diversity, and can play a decisive role in relation to local economic development $[25,46-48]$.

To account for the density and diversity both of people and of the activities, our evaluation model includes two sub-indices: a score, designated with $P$, for the density of residential population; and a score, designated with $A$, jointly scoring the density and diversity of activities and points of interest around the park.

Short blocks and diversity of buildings are not directly represented in the model. However, given that Jacobs largely considers these features as factors for greater density and diversity of activities on the ground, the joint score for density and diversity $A$ could be considered as indirectly representative of these two urban features.

As we will see more in detail below, to model the strength of the effect diminishing with the distance from the park, we define a series of concentric, increasingly larger catchment zones around the park, which are used to weight the importance of the residential population and of the activities, in order to compute the values of the two sub-indices $P$ and $A$.

\subsection{Intrinsic Factors: Design Qualities of Neighbourhood Parks}

Notwithstanding her emphasis on the parks' surrounding, Jacobs does not disregard the possibility of a positive impact a good architectural and urban design may have on urban parks' vitality. She identifies four elements of park design which promote their use: "enclosure", "intricacy", "centering" and "sun" [1] (p. 203). In discussing these design aspects, she touches on features subsequently widely explored by scholars and practitioners of urban design, but also recognised at the time of Jacobs's writing ("Other authors and researchers [... ] were also exposing the unworkability and joylessness of anti-city visions. In London, editors and writers of The Architectural Review were already up to the same thing in the mid-1950s" [1]). Despite some differences, both in theoretical approaches and in the practical vision of the urban project $[25,49,50]$, and not without some controversies, such criticism for modernist planning combined with interest for spaces of everyday life and vibrant built environments from the perspective of the pedestrian, can be recognised in many subsequent urban design, planning and social agendas. To mention just a few precursors among many, elements of such thrust can be found in the combination of descriptions and prescriptions in Gordon Cullen's Townscape, a visual anthology of articles published in The Architectural Review between 1947 and 1956 [51] focused on aesthetic and symbolic values of the city [52,53]; in Kevin Lynch's The Image of the City [54], which provides a more theoretical method to understand urban form and its use through the relationship between physical element and people's perception; in Christopher Alexander's A City is not a Tree [55] and Pattern Language [56], which follow Jacobs's ideas on complexity and relationship between design, buildings and city activities [57] to propose general guiding principles for design; 
and in Gehl's Life between Buildings [58], which provides a set of procedures for the analysis of interaction between public spaces and public life.

Drawing substantially on Jacobs's theory, but also integrating some elements of that subsequent body of studies, for our evaluation model we evaluate four park design features: (1) interplay with the surroundings, (2) intricacy, (3) salience, and (4) microclimate.

Interplay with the surroundings. Jacobs notes that "the presence of buildings around a park is important in design. They enclose it. They make a definite shape out of the space, so that it appears as an important event in the city scene, a positive feature, rather than a no-account leftover" [1]. In this context, enclosure relates to the form, spatial delimitation and integration of the park with its surrounding urban area, relevant for its role in the city scenery [1]. It combines the interplay of integrations, but also separations and enclosures which contribute to determine not only the park's accessibility, but also its identity, visibility and recognisability, thus representing an important factor of attraction for visitors. These characteristics hinge greatly on the presence of physical elements (e.g., buildings, walls, fences, trees) that visually define the boundary of the park [53]. As Alexander et al. [56] observed, "an outdoor space is positive when it has a distinct and definitive shape, as definite as the shape of a room, and when its shape is as important as the shapes of the buildings that surround it". In this sense, we also evaluate the degree of interaction of the park with the adjacent streets [59] which, as access lines, jeopardise its visibility and convenient accessibility [60].

Intricacy is associated with the variety of reasons and purposes people find to go to the parks. Jacobs claimed that parks are created to become places of different activities for diverse groups of users. Therefore, the presence of distinct "functional places" (e.g., for playing, walking, sport, meeting, reading) must be considered. In this respect, "Intricacy that counts is mainly intricacy at eye level, change in the rise of ground, groupings of trees, openings leading to various focal points-in short, subtle expressions of difference. The subtle differences in setting are then exaggerated by the differences in use that grow up among them" [1] (p. 104).

Salience jointly accounts for the feature of "centering" and the presence of "climaxes" from Jacobs's analysis of urban parks [1] (Ch. 5), together with the "tools" to obtain them through the physical elements in the park that make it more noticeable, prominent, recognisable and memorable, following Jacobs's observations on visual order, and the possibilities of distinctive urban elements (focal points, landmarks, buildings) [1] (Ch. 19) in the urban scenery. Among the elements strengthening the feature of salience we put (a) the presence of physical objects that constitute architectural landmarks (e.g., buildings, monuments, fountains, etc.); (b) elements of particular interest, from a natural (ecological value), historical (heritage value) and socio-cultural point of view (community identification). These elements can define a stable focus in the urban scene and promote the collective sense of place and place identity. In this sense, features of salience entertain a connection with the concept of imageability and focal points from Kevin Lynch's analysis [54].

Finally, microclimate. Jacobs considers the sun as part of "a park's setting for people" highlighting, in particular, the negative effects of the shadow cast by the adjacent buildings inside the park. We have extended this concept in order to evaluate, more generally, the microclimate present in the park, also according to the characteristics of the green in it. Although Jane Jacobs is, at times, sceptical of the strictly environmental benefits of urban green ("It takes about three acres of woods to absorb as much carbon dioxide as four people exude in breathing, cooking and heating" [1]) she recognises its potential recreational and experiential value, together with that of providing environmental comfort to the visitors. In this paper we consider this attribute especially in terms of internal microclimate and comfort which make the park pleasant to stay in [61-64]. Thus, part of this evaluation is also related to the park's "greenness", the overall green surface, combining grass, shrubs, and trees coverage.

Differently from the extrinsic factors of density and diversity, which are clearly measurable quantities to be used in the evaluation model, to evaluate each park on the four intrinsic factors (interplay with the surrounding, intricacy, salience and microclimate), we use evaluative judgements elicited 
by a panel of experts (architects and urban planners) through a specifically designed protocol described below (see Section 4.2, "Step 3").

\section{The Evaluation Model for Neighborhood Park Vitality Potential (NPV-potential)}

Having defined the essential ingredients of our evaluation model, we can now present how they are evaluated and combined to obtain the aggregate score of NPV-potential. The score is based on the weighted sum of the three sub-scores, $P, A$ and $D$ :

$$
\text { NPV-potential }=w_{P} P+w_{A} A+w_{D} D
$$

where:

- $\quad P$ is a score for the density of residential population within the park's catchment area;

- $A$ is a score for the diversity and density of activities within the catchment area;

- $D$ is a score for the park's internal organisation and design;

- $w_{P}, w_{A}, w_{D}$ are the respective weights of the three scores, with $w_{P}+w_{A}+w_{D}=1$.

\subsection{The Sub-Indicator $P$}

We define the score $P$ as:

$$
P= \begin{cases}\frac{\pi}{\pi_{\max }}, & \text { if } \pi<\pi_{\max } \\ 1, & \text { if } \pi \geq \pi_{\max }\end{cases}
$$

where $\pi_{\max }$ is a coefficient used for score rescaling and maximum cut-off (to obtain $P \in[0,1]$ ) and $\pi$ is defined as:

$$
\pi=\sum_{i=1}^{n} c_{i} \delta_{i} \rho_{i}
$$

where:

- $n$ is the number of concentric catchment zones;

- $c_{i} \in[0.5,1]$ is a reduction coefficient to account for the competition from other parks located within the $i$-th catchment zone (we model the competition from other parks to account for Jacobs's observation in that direction: «Outstandingly successful neighborhood parks seldom have much competition from other open spaces. This is understandable, because people in cities, with all their other interests and duties, can hardly enliven unlimited amounts of local, generalized park» [1] (Ch. 5)); the coefficient is based on the percentage of catchment zone's area overlapping with concurrent catchment zones of adjacent parks $\left(c_{i}\right.$ assumes value 1 if there are no other parks with catchment zones overlapping the $i$-th catchment zone of the park under consideration, and is reduced down to 0.5 , in case the entire $i$-th catchment zone overlapping with concurrent catchment zones from other adjacent parks);

- $\delta_{i} \in\langle 0,1]$ is the weight of the $i$-th catchment zone (the maximum value of 1 , attributed to the zone adjacent to the park, is progressively reduced for the more distant zones);

- $\quad \rho_{i}$ is the population residing within the $i$-th catchment zone.

\subsection{The Sub-Indicator A}

The score $A$ aggregates the information about the quantity and the diversity of activities and points of interest within the catchment zones around the park. To compute the score, preliminarily the activities are classified by type. Given $m$ types of activities, we define $A$ as:

$$
A= \begin{cases}\frac{\alpha}{\alpha_{\max }}, & \text { if } \alpha<\alpha_{\max } \\ 1, & \text { if } \alpha \geq \alpha_{\max }\end{cases}
$$


where $\alpha_{\max }$ is a coefficient used for score rescaling and maximum cut-off (to obtain $A \in[0,1]$ ) and $\alpha$ is defined as:

$$
\alpha=\prod_{j=1}^{m}\left(\sum_{i=1}^{n} c_{i} \delta_{i} a_{j, i}\right)^{w_{j}}
$$

where:

- $\quad m$ is the number of the activity types and $n$ is the number of concentric catchment zones;

- $\quad c_{i}$ and $\delta_{i}$ have the same meaning as in Equation (3);

- $a_{j, i}$ is the number of activities of $j$-th type present in the $i$-th catchment zone;

- $w_{j}$ is the weight factor of the $j$-th activity type (with $w_{1}+\ldots+w_{n}=1$ ).

The rationale for such a modelling of the score $A$, based on the product of contributions by each activity type (corrected for distance and competition from other parks, and raised to the power of $w_{j}$ ), is to account for interactions between activities as beneficial for the overall vitality. Furthermore, the modelling exhibits a plausible feature of diminishing marginal benefit of individual activity types on the overall vitality.

\subsection{The Sub-Indicator D}

The sub-indicator $D$ is an aggregate score of a qualitative evaluation of the park's design features. As we said, differently from the factors of density and diversity $P$ and $A$, which are measurable quantities, to evaluate each park on the four intrinsic factors (interplay with the surrounding, intricacy, salience and microclimate), we use evaluative judgements elicited by a panel of experts (architects and urban planners) on a three-level Likert-type scale (Low (1), Intermediate (2), High (3) for each factor. (See below Section 4.2, "Step 3" for the specific protocol used to obtain these evaluations).

Once the evaluative judgements of the design features from the panel of experts are obtained, the sub-indicator $D$ is constructed as the weighted sum of these design features, i.e.,

$$
D=\sum_{i=1}^{z} w_{i} x_{i}
$$

where $z$ is the number of design features (in our case $z=4$ ), $x_{i}$ is the qualitative judgment for the $i$-th design feature of the park and $w_{i}$ is the weight of that feature.

\section{An Exploratory Case Study}

To showcase the evaluation model, we present an application to three neighbourhood parks in the city of Cagliari, Italy. The main purpose of the application is to explore how the NPV-potential relates to the effective observable uses of the parks. For that, besides computing the NPV-potential for each park, we have conducted a direct observation of their effective uses.

The three parks (shown in Figures 2 and 3) present analogies with park types described by Jane Jacobs, and hence represent three significant cases:

- "Parco Lyons" (P1, area 20,200 $\mathrm{m}^{2}$ ) is a case of a "well-designed" park, with a wide range of equipment, but localised in a more peripheral area of the city; despite its relatively good design, the park is not very popular nor used;

- "Parco della Musica" (P2, area 27,110 $\mathrm{m}^{2}$ ) is a classic example of a park located in a central and lively urban context, with a lot of spaces and facilities that allow density and diversity of activities, resulting in more intensive use throughout the day; although not among the largest public parks in Cagliari, it is well known among neighbourhood residents and a broad section of city users;

- "Piazza Islanda" (P3, area $4050 \mathrm{~m}^{2}$ ) is a smaller park located in a semi-peripheral area with a predominantly residential vocation; the residential neighbourhood that surrounds the park 
is without big urban attractors, and is therefore characterised by a limited types of activities, resulting in a predominant use only during certain times of the day.

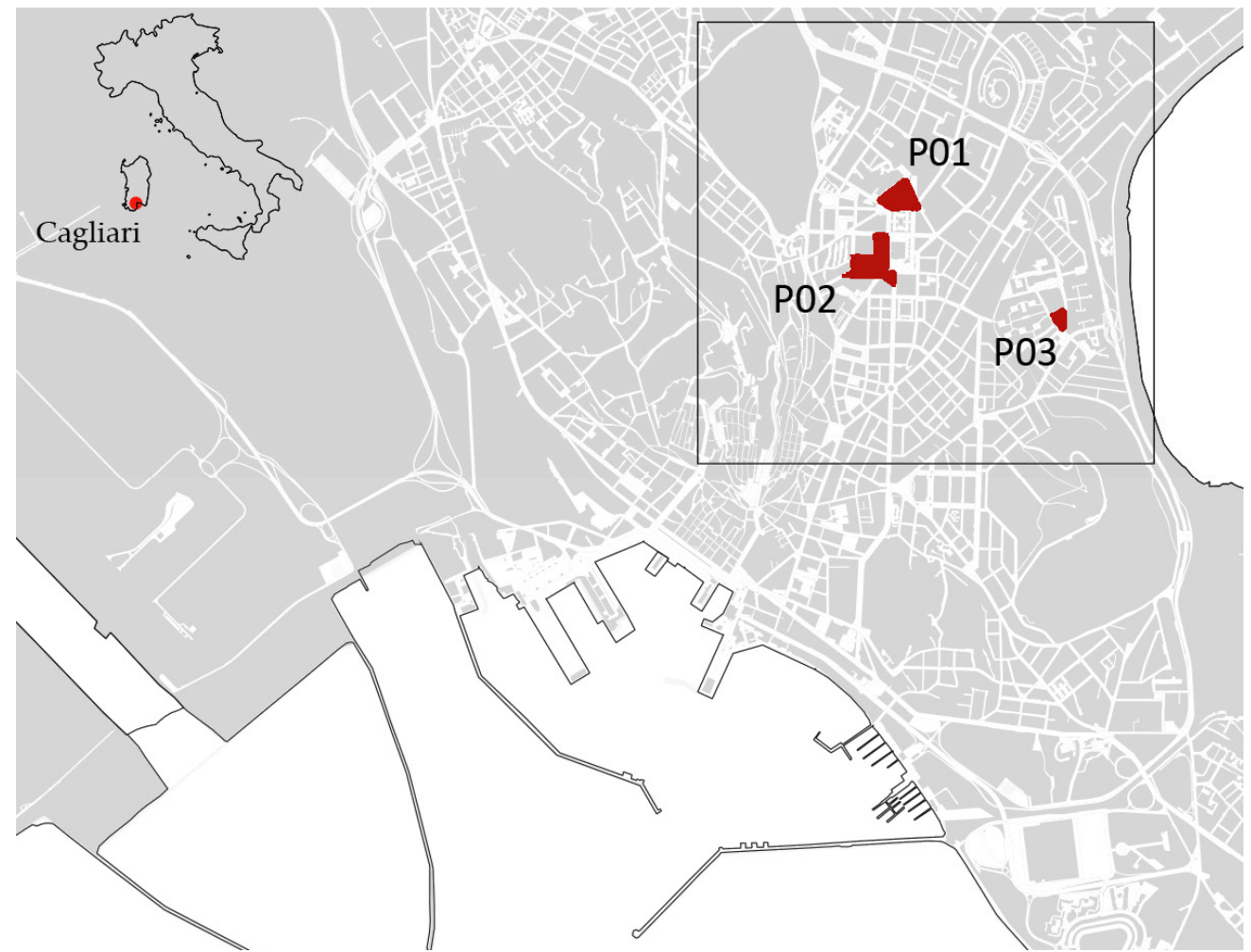

Figure 2. Three selected neighborhood parks in the city of Cagliari.
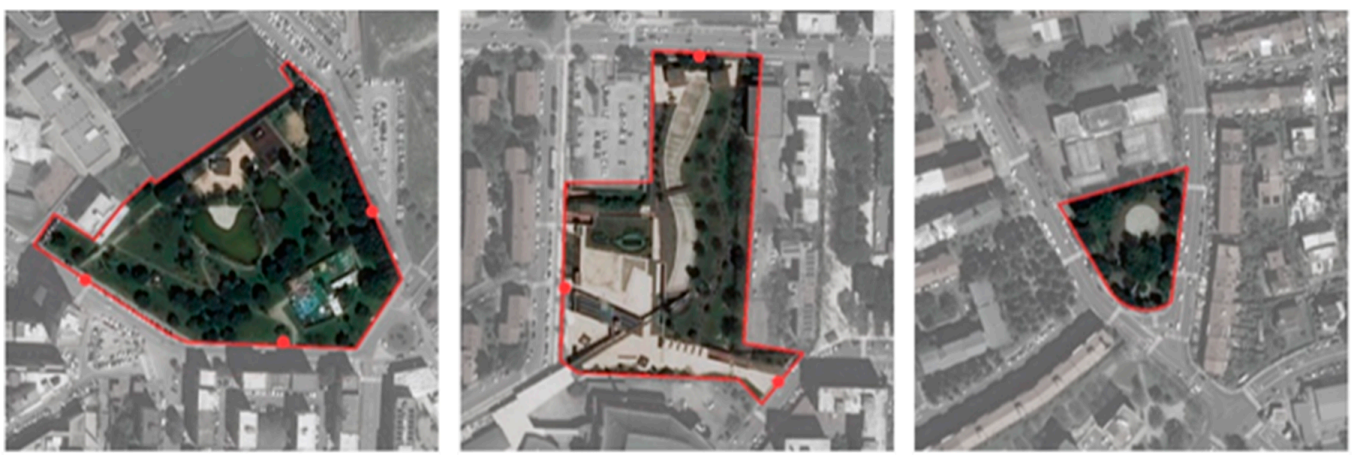

(a)
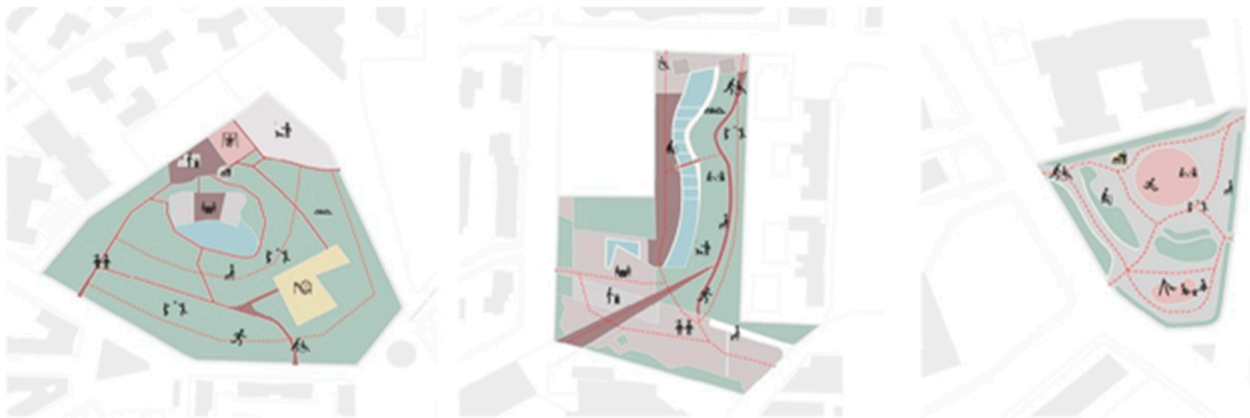

(b)

Figure 3. (a) Aerial view of the three parks, showing the boundaries and the points of access (the third park is open form); (b) schemes of parks' main design characteristics. 


\subsection{Calculating the NPV-potential}

The procedure for calculating the NPV-potential can be divided into three steps.

Step 1. Identification of the catchment zones. The first step is identifying the areas of influence of each park (catchment zones) based on pedestrian accessibility. For that, for each entry point to the park, we have defined three catchment zones with boundaries at the distances of $150 \mathrm{~m}, 300 \mathrm{~m}$ and $500 \mathrm{~m}$, respectively, to approximate walking times of 2, 4 and $7 \mathrm{~min}$ (Figure 4). The choice of $500 \mathrm{~m}$ for the maximum distance of the largest catchment zone reflects the findings and common planning recommendations (oscillating from 300 to $800 \mathrm{~m}$ ) [65] for a neighbourhood park to be perceived as very accessible by foot. A relevant feature of our model is that the catchment zones are not based on circular as-the-crow-flies distances, but were delimited using actual street-network distances, thus accounting indirectly for permeability and connectivity of the street layout.

Step 2. Density and diversity of residential population and activities. Using Google Maps with a direct validation on a sample of cases, we have collected the data on available activities/points of interest for each catchment zone, shown in Figure 4. To obtain the residential population within each catchment zone, we have used the municipal registry of residents. A possible limitation of this dataset is that we have not considered temporary inhabitants (not registered officially as residents in Cagliari, e.g., students, temporary workers), which may, in some cases, represent a significant quota of users. The number of activities and the residential population per each catchment zone is shown in Table 1.

Step 3. Evaluation of Design Quality. As presented above, to perform a qualitative assessment of their design characteristics, we have obtained the evaluative judgements from a panel of experts for each park on four criteria: (1) interplay with the surroundings; (2) intricacy; (3) salience; (4) microclimate.

Specifically, for this case study, the panel was composed of three architects and urban planners. In the first meeting we presented to the panellists the purpose and the scope of the research, together with making them acquainted with the meaning of the four factors (interplay with the surrounding, intricacy, salience and microclimate) and the levels of the qualitative evaluation scale.

The panellists were then invited to visit the three parks, on three different days, and separately from each other, with the specific recommendation to focus their attention on the four design features, dismissing possible conditioning from the observed practices of use of the parks. After that, the panellists were summoned on a second meeting, presented with plans and photographic documentation of the three parks, and invited each to elicit, independently from each other, their overall qualitative judgements of the three parks on each of the four design features.

Finally, the individual judgements were disclosed among the panellists, and they were invited to engage in a discussion and to arrive at a consensus evaluation. The following is a summary of the main qualitative observations and comments by the panellists on the three parks, together with their final consensus evaluations, reported in Table 2.

1. Interplay with the surroundings. Among the three parks, $\mathrm{P} 1$ is the most disadvantaged from this point of view. The perimeter of the park, in fact, shows conditions unfavourable to its use, due to the presence of high-speed roads that limit pedestrian crossing, an unpaved and abandoned area which borders the park, and a poorly permeable boundary due to the adjacent tall buildings. Moreover, the steep slopes of the internal landscape do not favour the parks' visibility from the entrances, nor do they encourage entering the park.

P2 is delimited by a high-speed street only on one side. In general, the park is characterised by a good sense of enclosure due to the permeability of the fence, which protects and delimits the park but makes it partially visible from the outside. Moreover, despite the presence of a park gate that limits access times, those who walk outside can easily see what is happening inside and are encouraged to enter. 
Table 1. Number of activities/points-of-interest and residential population per catchment zone.

\begin{tabular}{|c|c|c|c|c|c|c|c|c|c|c|c|}
\hline & \multicolumn{10}{|c|}{ Activities } & \multirow[b]{2}{*}{ Population } \\
\hline & Services & $\begin{array}{l}\text { Health } \\
\text { Services }\end{array}$ & $\begin{array}{l}\text { Culture and } \\
\text { Religion }\end{array}$ & Education & $\begin{array}{l}\text { Small Food } \\
\text { and Grocery } \\
\text { Stores }\end{array}$ & Supermarkets & $\begin{array}{l}\text { Stores, Shops, } \\
\text { Business }\end{array}$ & $\begin{array}{c}\text { Bar and Small } \\
\text { Fast Food } \\
\text { Restaurant }\end{array}$ & $\begin{array}{l}\text { Restaurants, } \\
\text { Pizzerias }\end{array}$ & $\begin{array}{c}\text { Commercial } \\
\text { Lodging (Hotels, } \\
\text { Hostels, B\&Bs) }\end{array}$ & \\
\hline \multicolumn{12}{|c|}{ P1. Parco Lyons } \\
\hline $0-150 \mathrm{~m}$ & 1 & 1 & 0 & 3 & 2 & 1 & 9 & 4 & 1 & 1 & 592 \\
\hline $150-300 \mathrm{~m}$ & 5 & 3 & 1 & 5 & 7 & 3 & 29 & 10 & 3 & 1 & 2292 \\
\hline $300-500 \mathrm{~m}$ & 10 & 8 & 5 & 11 & 15 & 4 & 60 & 24 & 5 & 1 & 5257 \\
\hline \multicolumn{12}{|c|}{ P2. Parco della Musica } \\
\hline $0-150 \mathrm{~m}$ & 4 & 6 & 3 & 2 & 3 & 1 & 22 & 8 & 3 & 1 & 1054 \\
\hline $150-300 \mathrm{~m}$ & 8 & 7 & 3 & 5 & 11 & 2 & 60 & 18 & 4 & 1 & 3518 \\
\hline $300-500 \mathrm{~m}$ & 19 & 12 & 4 & 13 & 25 & 6 & 126 & 41 & 8 & 1 & 7057 \\
\hline \multicolumn{12}{|c|}{ P3. Piazza Islanda } \\
\hline $0-150 \mathrm{~m}$ & 0 & 0 & 0 & 2 & 0 & 0 & 2 & 1 & 0 & 0 & 511 \\
\hline $150-300 \mathrm{~m}$ & 0 & 2 & 0 & 2 & 0 & 1 & 13 & 3 & 1 & 0 & 1684 \\
\hline $300-500 \mathrm{~m}$ & 2 & 5 & 1 & 3 & 1 & 1 & 31 & 6 & 1 & 0 & 3359 \\
\hline
\end{tabular}



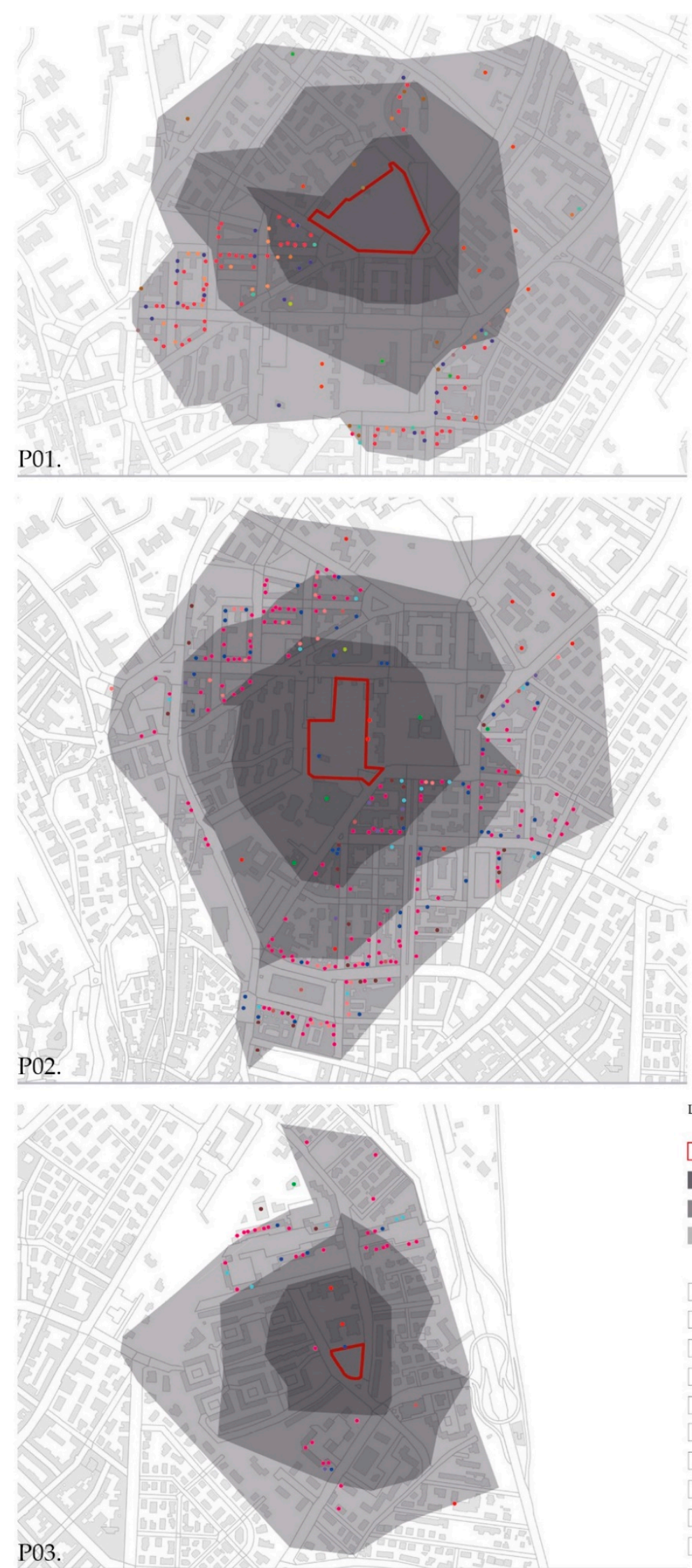

LEGENDA
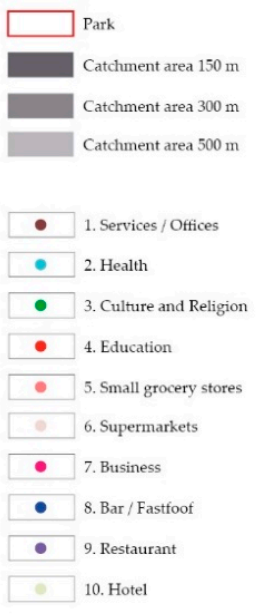

Figure 4. Catchment zones and activities for the three parks: P01 "Parco Lyons", P02 "Parco della Musica, P03 "Piazza Islanda". 
Table 2. Design Quality scores.

\begin{tabular}{cccccc}
\hline & $\begin{array}{c}\text { Interplay with } \\
\text { Surroundings }\end{array}$ & Intricacy & Salience & Microclimate & Total \\
\hline 01. Parco Lyons & Low (1) & Low (1) & Low (1) & Intermediate (2) & 6 \\
\hline 02. Parco della Musica & High (3) & High (3) & High (3) & Intermediate (2) & 11 \\
\hline 03. Piazza Islanda & High (3) & Intermediate (2) & Intermediate (2) & Low (1) & 8 \\
\hline
\end{tabular}

Unlike the other two parks, P3 has excellent visibility thanks to its central position with respect to the road system and to the fact that it is not delimited by closed fences. The only delimitation is given by a low concrete wall that runs along the entire perimeter, interrupted at four equidistant access points. Despite the fact that the features of the perimeter do not favour a sense of protection and delimitation, the park's visibility makes the park relatively attractive with respect to the surrounding urban scenery.

2. Intricacy. P1 has a compact and regular shape, and all the internal areas converge towards a central point, located at the highest altitude. The steepness of the terrain puts constraints on internal walkability, also because the spatial organisation is somewhat confusing. Despite the presence of different functional zones (recreational, sport, refreshment point, children's play area), in fact, these are dispersed within the large area of the park without a clear organisation of the pedestrian routes.

The internal distribution of $\mathrm{P} 2$ is well designed and implemented. There are a variety of spaces, distinguished by function, type of greenery, lighting, and pavement materials. The focal point is an artificial lake, which extends along the entire length of the park. Although there is no stringent hierarchy of spaces, the design is clear and orderly. At each access point there are spaces with different equipment that allow people to use the park without having to walk along the entire area. Generally, the park is used for different activities and its flat paths are pleasantly used for walking and for pedestrian activities. The small slope variations, in fact, are designed in such a way as to be gradual and pleasant. Thanks to these features, the park is easily accessible and safe even for people with disabilities, children, and senior citizens. In P3, the clear spatial organisation makes the park easily accessible and usable. All paths, characterised by sinusoidal shapes, converge to a central rest area, which represents the focal point of the park, making the walks welcoming. A small playground area has been recently created which is very popular with the neighbourhood's children.

3. Salience. In P1 there are no architectural, historical-cultural or environmental elements drawing particular interest. The park is, therefore, hardly recognisable and attractive to the population who do not reside in the nearby area. $\mathrm{P} 2$ also does not possess elements of particular interest in themselves, but the presence of many peculiar elements makes the park recognisable and attractive. Among these, the artificial lake represents one of the most recognisable elements also for the central role it plays in the organisation of the internal space. P3 is not well equipped with valuable or particularly recognisable elements. Despite this, the park is recognisable because it is one of the few public spaces in the area, located in a very visible position.

4. Microclimate. Most of the P1 surface is covered by vegetation. There are trees of various species, with semi-dense-to-dense fronds, and surfaces covered with grass. These characteristics make the park pleasant from a climatic point of view. However, the dense presence of trees leads some areas to be in shadow for most of the day, making them damp and less usable during the autumn and winter months. In P2 the green surfaces are significant and cover more than half of the park's extension. The presence of greenery is balanced with respect to the entire internal organisation of the park. There are areas with trees and grass, and others with only medium-sized plants enclosed in the flower beds. The tree frond is not very dense and allows for the easy filtering of sunlight, thus ensuring adequate sunshine in all areas of the park. This characteristic makes the park pleasant for use during all months of the year. P3 has a good amount of greenery but little variety. In this park, in fact, there are thick trees, concentrated in some areas, inside flower beds. The rest of the square is made of waterproof cement-based flooring that does not perform well under the microclimatic profile. 
Based on these observations and judgements, the panel of experts have agreed to attribute synthetic evaluations shown in Table 2.

Having presented the input data for both the extrinsic and the intrinsic factors of vitality, in Table 3 we summarise the parameters of the model employed for the evaluation (following the notation from Section 3).

Table 3. Values of the evaluation model parameter employed for the evaluation.

\begin{tabular}{|c|c|c|c|}
\hline Parameters & Eqs. & Values & Description and Notes \\
\hline$w_{p}, w_{A}, w_{D}$ & (1) & $1 / 3,1 / 3,1 / 3$ & Weights of sub-indices $P, A$, and $D$ \\
\hline$n$ & (3), (5) & 3 & $\begin{array}{l}\text { Three concentric catchment zones: (1) } 0-150 \mathrm{~m} \text {; } \\
\text { (2) } 150-300 \mathrm{~m} \text {; (3) } 300-500 \mathrm{~m}\end{array}$ \\
\hline$\delta_{i}$ & (3), (5) & $(1,0.5,0.25)$ & Weights of the three concentric catchment zones \\
\hline$m$ & (5) & 4 & $\begin{array}{l}\text { Four types of activities: (1) grouping services, } \\
\text { health services, and culture and religion); (2) grouping small } \\
\text { food and grocery stores; supermarkets; and stores, shops and } \\
\text { businesses; (3) schools; (4) grouping bar and small fast food; } \\
\text { restaurants and pizzerias; commercial lodging (hotels). }\end{array}$ \\
\hline$\pi_{\max }$ & (4) & 4000 & Population scaling and cut-off parameter \\
\hline$\alpha_{\max }$ & (2) & 100 & Activity scaling and cut-off parameter \\
\hline$w_{j}$ & (5) & 0.25 & $\begin{array}{l}\text { Weighting parameter for each type of activities } \\
\text { (equal for each of the } 4 \text { types) }\end{array}$ \\
\hline$z$ & (6) & 4 & $\begin{array}{l}\text { Four design features: (1) interplay with the surroundings; } \\
\text { (2) intricacy; (3) salience; (4) microclimate. }\end{array}$ \\
\hline$w_{i}$ & (6) & 0.25 & $\begin{array}{l}\text { Weights of the design features } \\
\text { (equal for each of the } 4 \text { features) }\end{array}$ \\
\hline
\end{tabular}

Based on the above presented input data (Tables 1 and 2) and model parameters (Table 3), we were able to compute the values of the sub-indices $P, A$ and $D$, and finally the overall NVP-potential. These results are reported in Table 4.

Table 4. NPV-potential: final scores.

\begin{tabular}{ccccc}
\hline Park & Population (P) & Activities (A) & Design (D) & NPV-potential \\
\hline P1. Parco Lyons & $53 / 100$ & $49 / 100$ & $50 / 100$ & $51 / 100$ \\
\hline P2. Parco della Musica & $78 / 100$ & $82 / 100$ & $92 / 100$ & $84 / 100$ \\
\hline P3 Piazza Islanda & $41 / 100$ & $16 / 100$ & $67 / 100$ & $41 / 100$ \\
\hline
\end{tabular}

\subsection{Direct Observation of Effective Uses and Vitality of the Parks}

To compare the NPV-potential scores with the situation on the ground, we have produced a systematic photographic documentation of the uses of the three parks, in order to assess their vitality through direct observation. The vitality has been assessed for three time slots: morning (10:00-13:00), early afternoon (13:00-16:00), and late afternoon to early evening (16:00-19:00). For each park, and for each time slot, the objective was to document and then to qualitatively assess three criteria: (1) the quantity of users; (2) the diversity of users (e.g., age, gender, nationality); and (3) the diversity of uses (e.g., play, talk, walk, etc.)

Following the protocol analogous to the one used for the qualitative evaluation of parks' design features (see above Section 4.2, "Step 3") but without another visit to the parks, we have submitted the photographic documentation to the same panel of experts to have them elicit evaluative judgements scoring each park, for each time slot, and on each of the three criteria, again on a three-level scale from 1 to 3 . The summary of these expert evaluations is reported in Table 5. 
Table 5. Observed uses of the three parks in the three time slots, with respect to the criteria of (a) users density; (b) users diversity; (c) intensity of use; scored by experts on a scale from 1 to 3 (scale 1-low, 2-average/intermediate, 3-high).

\begin{tabular}{ccccccccccc}
\hline Time Slot & \multicolumn{1}{c}{$10.00-13.00 \mathrm{~h}$} & \multicolumn{1}{r}{$13.00-16.00 \mathrm{~h}$} & \multicolumn{1}{r}{$16.00-19.00 \mathrm{~h}$} \\
\hline Criteria & $\mathrm{a}$ & $\mathrm{b}$ & $\mathrm{c}$ & $\mathrm{a}$ & $\mathrm{b}$ & $\mathrm{c}$ & $\mathrm{a}$ & $\mathrm{b}$ & $\mathrm{c}$ \\
\hline P1. Parco Lyons & 1 & 1 & 2 & 1 & 2 & 2 & 2 & 2 & 2 \\
\hline P2. Parco della Musica & 3 & 3 & 3 & 1 & 2 & 1 & 2 & 3 & 3 \\
\hline P3. Piazza Islanda & 1 & 1 & 1 & 1 & 2 & 2 & 3 & 3 & 3 \\
\hline
\end{tabular}

\subsection{Discussion of the Results}

In qualitative terms, the direct observation has allowed us to verify that P1 and P2 offer diversified spaces for several activities, but with different overall design qualities. It is important to recall that the two parks are located not far from each other (see above Figure 2) but lay along a strip of transition from a central to a more peripheral area of the city. Hence, although relatively nearby, P1 and P2 are sitting in two urban contexts notably different in terms of density and diversity of activities (see Figure 4), with P1 having a more peripheral, and P2 a more central character. This fact is among the most likely cause of their different vitality: P1 is used less and more sporadically throughout the day; only the small playground area located near one of the access points is intensely used but only in certain hours of the day; instead, P2 is used more intensely, by people of different types and ages, and throughout the day. These findings are in accordance with Jacobs's expectation, being that P2 is located in a highly diverse context, with numerous and diversified commercial activities, while P1 is placed in a context with fewer nearby activities. Moreover, a high-rise building bordering one side of P1 has an isolating effect, limiting the visual opening towards the park.

P3, although located in a predominantly residential neighbourhood, with a relatively low value of the activity sub-index $A$, exhibits a dual use profile: sporadic in the morning, and steady in the afternoon. The observation of the context allows us to verify the presence of a school complex built adjacent to the park, and of a supermarket. The rest of the surrounding area is predominantly residential. Positive factors for the park's use are represented by its visibility, its centrality with respect to the neighbourhood road network, and the fact that it is not confined by the built areas. Furthermore, it is one of the few large public spaces in the neighbourhood, the others being much smaller and surrounded by building blocks, making them less inviting for use by the non-residents. For all these reasons, the park is welcoming, perceived as safe and suitable for play.

Overall, the exercise of direct observation of the effective uses of the three parks makes it possible to arrive at the general qualitative judgement that $\mathrm{P} 2$ shows the greatest vitality among the three studied parks. P1 and P3 showed an intermediate-to-low vitality, but with a different use profile. P1 has a more or less uniform intermediate intensity of use throughout the day, and P3 has a dual use profile: scarce in the morning time slot, and more intensive in the afternoon.

Comparing these evaluative judgements from the direct observation of the three parks with their calculated NPV-potential (P1: 51/100, P2: 84/100 and P3: 41/100), we can ascertain a good qualitative agreement between the two.

There is a notable difference in NPV-potential between the three parks. This result is largely dependent on the differences in their components $P$ and $A$. Parks P1 and P2 have a different value of NPV-potential despite being nearby, and, therefore, with somewhat overlapping outer catchment zones. This competition, suggested as a possibility by Jane Jacobs, is duly accounted by the evaluation model. The relatively low NPV-potential of P3 is attributable primarily to the values of sub-indices $A$ and $P$. The value of $A$ is particularly lacking: the activities are few and not located within the catchment zone immediately adjacent to the park.

These results are consistent with the outcomes of the exercise of direct observation of the parks' vitality. The variability in our three cases is also consistent with Jane Jacobs hypothesis that the vitality 
largely hinges on the characteristics of the parks' surroundings, in our case their catchment areas. A greater density and diversity of uses and activities draw a larger number of people to the urban area, that the park can then attract. The higher the number of people moving in the park's surrounding area, the safer the park is perceived, gaining the intensity and frequency of users who constantly animate it, guaranteeing its liveliness and motivating its existence.

As we suggested, the possible competition between parks may be a relevant factor for the difference in vitality between P2 and P1. The fact that P2 and P1 share an activity-populated zone to the north, but there are no parks "contesting" the activities in the southern parts of P2's catchment area, is a factor of $\mathrm{P} 2$ 's relatively greater vitality.

As we said, P3 exhibits a dual use profile: sporadic in the morning, and vital during the afternoon hours of the day. Many of the park's "shortcomings" (relative lack of surrounding activities, mediocre design) are compensated by its prominent position within the neighbourhood, and by the residents recognizing it as a "symbolic" public space, a focal and a meeting point of the neighbourhood.

Although the differences in vitality and use between P1 and P3 are not reflected in the values of their aggregate NPV-potential, it may have been expected with respect to the values of their respective sub-indices. Indeed, a relatively greater density and variety of activities (sub-index $A$ ) around $\mathrm{P} 1$ is reflected in its being more regularly, albeit not very intensively, used throughout the day. Instead, the relative lack of activities (low value of $A$ ) but a greater population density of residential population around $\mathrm{P} 3$ yields its dual use profile, with a predominantly residential population using the park in the afternoon.

\section{Conclusions}

The findings of this study bring evidence for a perhaps obvious, but not seldom shrugged at teaching of Jane Jacobs: that it is people who attract other people, and that a good park project is moulded foremost from the material of its urban context and surrounding.

Obviously, the results of this study cannot be considered a robust validation of the NPV-potential as predictive of the actual vitality of urban parks. That claim would require more extensive empirical study, with larger and more internally variable samples of parks and surrounding conditions. Hence, the reported agreement between the potential and the observed vitality on the ground should be considered only as preliminarily indicative and suggests the potential usefulness of further studies.

However, the results of the example application point at the possible usefulness of the proposed evaluation method for urban planning. Rather than strictly predictive, its purpose may show up as a method to more explicitly and formally treat, explore, and incorporate Jacobs's insights into planning and policy making.

For instance, one possible use of the NPV-potential is to evaluate interventions and policies to encourage the use of low-vitality parks, through a study of the urban context and the real needs expressed by the users; for example, by means of the organisation of focus groups and meetings with citizenship and interested authorities. A multi-level and collaborative approach to urban green space governance may be beneficial for building institutional resilience [66] and for achieving economic, social, and environmental benefits (e.g., see [67]).

Furthermore, the NPV-potential could be helpful in defining the localisation criteria for the projects of new green areas in the city. Hence, the NPV-potential can be placed among the tools of a planners' toolbox not so much for the evaluation of existing green areas as in our application, but in the context of feasibility studies, as a tool supporting decision-making processes, useful for orienting and assessing the choices of location for future green areas, helping to avoid falling into the "pitfalls of sustainable city" [68]. In this context, the proposed methodology could provide a potential tool for the maintenance and the improvement of urban ecosystem services, in order to reduce their spatial mismatches across the city and to ensure equal opportunities for all inhabitants. From this point of view, the evaluation of the catchment ecosystem services could allow us to define strategic prioritisation of land-use options and to optimise the allocation of funds. In particular, the methodology offers the 
opportunity for an adaptive and iterative governance approach which is considered particularly useful for this purpose [69].

Besides a more extensive validation effort, there are ways in which the NPV-potential can be extended and further developed. A possible extension would be to develop more automated procedures to collect data and perhaps even to assign qualitative judgments using machine learning techniques [70]. Furthermore, it would be possible to develop a more detailed approach to account for pedestrian accessibility, based on individual distances of the activities, instead of the coarse-grained approach of catchment zones, and by incorporating assessments of walkability [71] instead of just distances.

Although there is still work to be done, and possible advancements to be made, we believe that the example application from this study, together with the indications, presented above, of the possible employment of the NPV-potential evaluation tool in different decision making contexts, account for its potential usefulness as a planning and design support tool at different scales of intervention.

Author Contributions: Conceptualisation and methodology, F.B., I.B., V.S. and G.A.T.; data curation, F.B., I.B., V.S.; formal analysis, I.B., V.S. and G.A.T.; writing-original draft preparation, I.B., V.S.; writing—review and editing, I.B., V.S. and G.A.T.; supervision, I.B. All authors have read and agreed to the published version of the manuscript.

Funding: This research received no external funding.

Conflicts of Interest: The authors declare no conflict of interest.

\section{References}

1. Jacobs, J. The Death and Life of Great American Cities; Penguin Random House: New York, NY, USA, 1961.

2. Barnett, A. Visionary Women: How Rachel Carson, Jane Jacobs, Jane Goodall, and Alice Waters Changed Our World; Eco Press: New York, NY, USA, 2018.

3. Goldsmith, S. Urban Ecology as the New Planning paradigm: Another legacy of Jane Jacobs. In Contemporary Perspectives on Jane Jacobs: Reassessing the Impacts of an Urban Visionary; Ashgate: Farnham, UK, 2014; pp. 225-232.

4. Kinkela, D. The Ecological Landscapes of Jane Jacobs and Rachel Carson. Am. Q. 2009, 61, 905-928. [CrossRef]

5. Rowan, J. The New York School of Urban Ecology: The New Yorker, Rachel Carson, and Jane Jacobs. Am. Lit. 2010, 82, 583-610. [CrossRef]

6. Jacobs, J. The Death and Life of Great American Cities; Modern Library: New York, NY, USA, 1993; ISBN 978-0-679-60047-3.

7. Carson, R. Silent Spring; Houghton Mifflin Company: Boston, MA, USA, 1962.

8. Lawrence, F. (Ed.) Ethics in Making a Living: The Jane Jacobs Conference; Scholars Press: Atlanta, GA, USA, 1989; ISBN 978-1-55540-368-3.

9. Bramiana, C.N.; Widiastuti, R.; Harsritanto, B.I. Implementing Mixed Land Use Rooting Jane Jacobs' Concept of Diversity in Urban Sustainability. Available online: https:/ejournal.undip.ac.id/index.php/modul/article/ view/17248 (accessed on 3 April 2019).

10. Mohareb, E.; Derrible, S.; Peiravian, F. Intersections of Jane Jacobs' Conditions for Diversity and Low-Carbon Urban Systems: A Look at Four Global Cities. J. Urban Plan. Dev. 2016, 142, 05015004. [CrossRef]

11. Scarlett, L. Introduction: Cities and Sustainability. Sustain. Dev. Law Policy 2011, 11, 2-3.

12. Jacobs, J. The Uses of Neighborhood Parks. In Small Urban Spaces: The Philosophy, Design, Sociology, and Politics of Vest-Pocket Parks and Other Small Urban Open Spaces; New York University Press: New York, NY, USA, 1969.

13. Barnett, A. Jane Jacobs and Designing Cities as Organized Complexity. In The Urban Wisdom of Jane Jacobs; Routledge: London, UK, 2012; pp. 245-266.

14. Desrochers, P. The Death and Life of a Reluctant Urban Icon. J. Libert. Stud. 2007, 21, 115-136.

15. Desrochers, P.; Leppälä, S. Opening up the "Jacobs Spillovers" black box: Local diversity, creativity and the processes underlying new combinations. J. Econ. Geogr. 2011, 11, 843-863. [CrossRef]

16. Ellerman, D. Jane Jacobs on Development. Oxf. Dev. Stud. 2004, 32, 507-521. [CrossRef]

17. Ellerman, D. How Do We Grow? Jane Jacobs on Diversification and Specialization. Challenge 2005, 48, 50-83. [CrossRef]

18. Fuller, M.; Moore, R. An Analysis of Jane Jacobs's The Death and Life of Great American Cities; Macat Library: London, UK, 2017; ISBN 978-1-912282-66-1. 
19. Gratz, R.B. The Battle for Gotham: New York in the Shadow of Robert Moses and Jane Jacobs; Nations Book: New York, NY, USA, 2010.

20. Hill, D.R. Jane Jacobs' Ideas on Big, Diverse Cities: A Review and Commentary. J. Am. Plan. Assoc. 1988, 54, 302-314. [CrossRef]

21. Hirt, S.; Zahm, D.; Zahm, D. The Urban Wisdom of Jane Jacobs; Routledge: Abingdon, UK, 2012; ISBN 978-0-203-09517-1.

22. Kanigel, R. Eyes on The Street: The Life of Jane Jacobs; Knopf: New York, NY, USA, 2016.

23. Mennel, T.; Steffens, J.; Klemek, C. (Eds.) Block by Block: Jane Jacobs; Princeton Architectural Press: New York, NY, USA, 2007; ISBN 978-1-56898-771-2.

24. Page, M.; Mennel, T. Reconsidering Jane Jacobs; APA Planners Press: Chicago, IL, USA, 2017.

25. Schubert, D. (Ed.) Contemporary Perspectives on Jane Jacobs: Reassessing the Impacts of an Urban Visionary; Ashgate: Farnham, UK, 2014; ISBN 978-1-4724-1004-7.

26. Seamon, D. 'A jumping, joyous urban jumble': Jane Jacobs's Death and Life of Great American Cities as a phenomenology of urban place. J. Space Syntax 2012, 3, 139-149.

27. Van den Berg, M. The discursive uses of Jane Jacobs for the genderfying city: Understanding the productions of space for post-Fordist gender notions. Urban Stud. 2018, 55, 751-766. [CrossRef]

28. Wendt, M. The Importance of Death and Life of Great American Cities (1961) by Jane Jacobs to the Profession of Urban Planning; University of Delaware Press: Newark, DE, USA, 2009.

29. Weicher, J.C. A test of Jane Jacobs' theory of successful neighborhoods. J. Reg. Sci. 1973, 13, 29-40. [CrossRef]

30. Sung, H.-G.; Go, D.-H.; Choi, C.G. Evidence of Jacobs's street life in the great Seoul city: Identifying the association of physical environment with walking activity on streets. Cities 2013, 35, 164-173. [CrossRef]

31. Sung, H.; Lee, S.; Cheon, S. Operationalizing Jane Jacobs's Urban Design Theory: Empirical Verification from the Great City of Seoul, Korea. J. Plan. Educ. Res. 2015, 35, 117-130. [CrossRef]

32. Sung, H.; Lee, S. Residential built environment and walking activity: Empirical evidence of Jane Jacobs' urban vitality. Transp. Res. Part D Transp. Environ. 2015, 41, 318-329. [CrossRef]

33. De Nadai, M.; Staiano, J.; Larcher, R.; Sebe, N.; Quercia, D.; Lepri, B. The Death and Life of Great Italian Cities: A Mobile Phone Data Perspective. In Proceedings of the 25th International Conference on World Wide Web, Montreal, QC, Canada, 11-15 April 2016; ACM Press: New York, NY, USA, 2016; pp. 413-423.

34. Delclòs-Alió, X.; Miralles-Guasch, C. Looking at Barcelona through Jane Jacobs's eyes: Mapping the basic conditions for urban vitality in a Mediterranean conurbation. Land Use Policy 2018, 75, 505-517. [CrossRef]

35. Sulis, P.; Manley, E.; Zhong, C.; Batty, M. Using mobility data as proxy for measuring urban vitality. J. Spat. Inf. Sci. 2018, 137-162. [CrossRef]

36. Bangs, H.P.; Mahler, S. Users of Local Parks. J. Am. Inst. Plan. 1970, 36, 330-334. [CrossRef]

37. Gold, S. Nonuse of Neighborhood Parks. J. Am. Inst. Plan. 1972, 38, 369-378. [CrossRef]

38. Gold, S.M. The Fate of Urban Parks. Parks Recreation. 1976, 11, 13-18.

39. Gold, S.M. Neighborhood Parks: The Nonuse Phenomenon. Eval. Q. 2016, 1, 319-327. [CrossRef]

40. Moore, M.; Jones, W. Recreation and Urban Park Planning: Problems and Prospects. J. Environ. Syst. 1981, 11, 315-323. [CrossRef]

41. Gans, H.J. City Planning in America: A Sociological Analysis; Basic Books: New York, NY, USA, 1968.

42. Jacobs, J. The Economy of Cities; Random House: New York, NY, USA, 1969.

43. Talen, E. The Spatial Logic of Parks. J. Urban Des. 2010, 15, 473-491. [CrossRef]

44. Montgomery, J. Making a city: Urbanity, vitality and urban design. J. Urban Des. 1998, 3, 93-116. [CrossRef]

45. Blečić, I.; Cecchini, A. Antifragile planning. Plan. Theory 2020, 19, 172-192. [CrossRef]

46. King, K. Jane Jacobs and 'The Need for Aged Buildings': Neighbourhood Historical Development Pace and Community Social Relations. Urban Stud. 2013, 50, 2407-2424. [CrossRef]

47. Moroni, S. Urban density after Jane Jacobs: The crucial role of diversity and emergence. CityTerrit. Archit. 2016, 3, 1-8. [CrossRef]

48. Powe, M.; Mabry, J.; Talen, E.; Mahmoudi, D. Jane Jacobs and the Value of Older, Smaller Buildings. J. Am. Plan. Assoc. 2016, 82, 167-180. [CrossRef]

49. Klemek, C. Placing Jane Jacobs within the Transatlantic Urban Conversation. J. Am. Plan. Assoc. 2007, 73, 49-67. [CrossRef]

50. Dempsey, N. Quality of the Built Environment in Urban Neighbourhoods. Plan. Pract. Res. 2008, 23, $249-264$. [CrossRef] 
51. Serrano, C.M. A City with a Sense Back to Kevin Lynch's the Image of the City. Diségno 2020, 5, 209-216.

52. Cullen, G. Townscape; Architectural Press: London, UK, 1961.

53. Cullen, G. The Coincise Townscape; Architectural Press: Oxford, UK, 1971.

54. Lynch, K. The Image of the City-Kevin Lynch-Google Libri; MIT Press: Cambridge, MA, USA, 1960.

55. Alexander, C. A city is Not a Tree. Archit. Forum 1965, 122, 58-62.

56. Alexander, C.; Ishikawa, S.; Silverstein, M.; Jacobson, M.; Fiksdahl-King, I.; Angel, S. Pattern Language; Oxford University Press: New York, NY, USA, 1977.

57. Laurence, P.L. Contradictions and Complexities: Jane Jacobs's and Robert Venturi's Complexity Theories. J. Archit. Educ. 2006, 59, 49-60. [CrossRef]

58. Gehl, J. Life Between Buildings: Using Public Space; Island Press: London, UK, 1987.

59. Whyte, W.H. The Social Life of Small Urban Spaces Whyte; The Conservation Foundation: Washington, DC, USA, 1980; Volume 10.

60. Ewing, R.; Handy, S. Measuring the Unmeasurable: Urban Design Qualities Related to Walkability. J. Urban Des. 2009, 14, 65-84. [CrossRef]

61. Stamps, A. Isovists, Enclosure, and Permeability Theory. Environ. Plan. B Plan. Des. 2005, 32, 735-762. [CrossRef]

62. Brown, R.; Vanos, J.; Kenny, N.; Lenzholzer, S. Designing urban parks that ameliorate the effects of climate change. Landsc. Urban Plan. 2015, 138, 118-131. [CrossRef]

63. Aram, F.; Solgi, E.; Higueras García, E.; Mosavi, A.; Várkonyi-Kóczy, A.R. The Cooling Effect of Large-Scale Urban Parks on Surrounding Area Thermal Comfort. Energies 2019, 12, 3904. [CrossRef]

64. Colter, K.R.; Middel, A.C.; Martin, C.A. Effects of natural and artificial shade on human thermal comfort in residential neighborhood parks of Phoenix, Arizona, USA. Urban For. Urban Green. 2019, 44, 126429. [CrossRef]

65. Guan, C.; Song, J.; Keith, M.; Akiyama, Y.; Shibasaki, R.; Sato, T. Delineating urban park catchment areas using mobile phone data: A case study of Tokyo. Comput. Environ. Urban Syst. 2020, 81, 101474. [CrossRef]

66. Buijs, A.E.; Mattijssen, T.J.; Van der Jagt, A.P.; Ambrose-Oji, B.; Andersson, E.; Elands, B.H.; Steen Møller, M. Active citizenship for urban green infrastructure: Fostering the diversity and dynamics of citizen contributions through mosaic governance. Curr. Opin. Environ. Sustain. 2016, 22, 1-6. [CrossRef]

67. Newig, J.; Fritsch, O. Environmental governance: Participatory, multi-level and effective? Environ. Policy Gov. 2009, 19, 197-214. [CrossRef]

68. Saiu, V. The Three Pitfalls of Sustainable City: A Conceptual Framework for Evaluating the Theory-Practice Gap. Sustainability 2017, 9, 2311. [CrossRef]

69. Green, O.O.; Garmestani, A.S.; Albro, S.; Ban, N.C.; Berland, A.; Burkman, C.E.; Gardiner, M.M.; Gunderson, L.; Hopton, M.E.; Schoon, M.L.; et al. Adaptive governance to promote ecosystem services in urban green spaces. Urban Ecosyst. 2016, 19, 77-93. [CrossRef]

70. Blečić, I.; Cecchini, A.; Trunfio, G.A. Towards Automatic Assessment of Perceived Walkability. In Lecture Notes in Computer Science, Proceedings of the Computational Science and Its Applications-ICCSA 2018, Melbourne, VIC, Australia, 2-5 July 2018; Gervasi, O., Murgante, B., Misra, S., Stankova, E., Torre, C.M., Rocha, A.M.A.C., Taniar, D., Apduhan, B.O., Tarantino, E., Ryu, Y., Eds.; Springer International Publishing: Cham, Switzerland, 2018; pp. 351-365.

71. Blečić, I.; Cecchini, A.; Congiu, T.; Fancello, G.; Trunfio, G.A. Evaluating walkability: A capability-wise planning and design support system. Int. J. Geogr. Inf. Sci. 2015, 29, 1350-1374. [CrossRef]

(C) 2020 by the authors. Licensee MDPI, Basel, Switzerland. This article is an open access article distributed under the terms and conditions of the Creative Commons Attribution (CC BY) license (http://creativecommons.org/licenses/by/4.0/). 